\title{
Trainees' perception of the postgraduate overseas medical training received in UK
}

\author{
Author: WD Dilshan Priyankara
}

\begin{abstract}
Aims
To identify key issues faced by post-doctor of medicine (MD) trainees, physician burnout and pattern of their lifestyle during overseas training in the UK.
\end{abstract}

\section{Methods}

This was an online survey among the post-MD graduates doing their overseas training in the UK. The survey was emailed to 89 post-MD trainees working in the UK during the survey period of December 2016 to January 2017, and 65 replied.

\section{Results}

Out of all the participants, 54 (83.1\%) were doing a paid job. More than $95 \%$ of trainees were working for 40 or more hours per week. In this survey, 28 (43.1\%) trainees were working below ST5 category. It has taken an average of 2.28 (standard deviation (SD) 1.74) months and 3.33 (SD 1.91) months to adapt to the hospital environment and adapt to the UK medical system respectively. In total, 32 (49.2\%) trainees did not have specific objectives prior to starting their overseas training. Among the trainees, 38 (58.5\%) felt that there was discrimination between them and UK trainees and $53.8 \%$ had a feeling of returning to Sri Lanka during their training. The majority of trainees felt burnt out, worn out and physically exhausted during their training and only 35 (53.9\%) were satisfied with their current job. Most of the trainees (37, 56.9\%) walked to the hospital. Fifty-two $(80 \%)$ of the trainees had their family in UK during the training period.

\section{Conflict of interest statement}

There is no conflict of interest. 